\title{
O lugar da sociologia da educação nas ciências da educação: o caso dos programas de mestrado e doutoramento portugueses
}

Camila Ferreira da Silva' Mariana Gaio Alves ${ }^{2}$

\section{Resumo}

Considerar analiticamente quaisquer áreas de investigação é um exercício que faz emergir questões de natureza conceitual, epistemológica e remete para lutas travadas em determinado campo científico para a legitimação de uma estrutura, de agentes, capitais e posições em jogo. Tal compreensão serviu de sustentáculo para o presente artigo, que tem como objectivo geral contribuir para um conhecimento mais amplo da Sociologia da Educação em Portugal. Para tal, a supracitada área foi tomada a partir de sua faceta enquanto área de docência em cursos de mestrado e doutoramento no âmbito das Ciências da Educação. A conjugação aqui realizada entre um apanhado sócio histórico, de um lado, e a caracterização actual a partir dos cursos supracitados, de outro, permitiu-nos compreender melhor o que é hoje legitimado como Sociologia da Educação, bem como o lugar que ela ocupa no espaço das Ciências da Educação.

Palavras-chave: Campo científico; Sociologia da Educação; Ciências da Educação; Portugal.

\section{Introdução}

A Sociologia da Educaçáo (SE) tem origens históricas, no plano internacional, que se confundem com a emergência da própria Sociologia enquanto disciplina científica nos finais do século XIX. Não obstante, a

Estudante de doutoramento em Ciências da Educação na Universidade Nova de Lisboa (Bolsista Erasmus Mundus).

2 Professora Auxiliar com Agregação na Faculdade de Ciência e Tecnologia da Universidade Nova de Lisboa. 
institucionalização da Sociologia de Educação em Portugal, ou seja o seu reconhecimento como área científica de pesquisa e de ensino, vai acontecendo progressivamente durante o século XX, sendo fortemente influenciada pelas transformaçóes políticas, sociais e económicas no país.

Sublinhe-se que em Portugal, tal como noutros países, o desenvolvimento da Sociologia da Educação ocorreu, desde o seu início, em dois contextos institucionais: o das Ciências da Educação (estreitamente ligadas à formaçáo de professores e outros educadores) e o da Sociologia (correspondente a formaçóes centradas nesta área científica vocacionadas para a formação de sociólogos). Tanto no plano da respectiva docência no ensino superior, quanto tendo em conta a investigação e conhecimento produzidos ou ainda as sociedades científicas e profissionais existentes, reconhece-se a existência de duas comunidades nem sempre exatamente coincidentes (AFONSO, 2010; ABRANTES, 2004). Neste artigo, procuramos contribuir para um conhecimento mais aprofundado da Sociologia da Educação enquanto área de magistério em cursos de mestrado e doutoramento em Ciências da Educação, no âmbito de um projeto de pesquisa mais amplo ${ }^{3}$ presentemente em desenvolvimento que procurará caracterizar este domínio científico de forma abrangente e aprofundada.

Para tal procura-se, em primeiro lugar, explicitar o design do estudo em curso. Numa segunda secçáo do artigo, sistematizam-se elementos reflexivos relativos ao desenvolvimento da Sociologia de Educação em Portugal, por forma a delinear um contexto adequado à interpretação dos dados apresentados na terceira secçáo do artigo. Para finalizar, enunciam-se algumas linhas conclusivas que, simultaneamente, apontam pistas de desenvolvimento futuro da pesquisa em curso.

\section{Design do estudo: epítome}

Compreender o lugar ocupado pela Sociologia da Educação no âmbito das chamadas Ciências da Educação em Portugal desenha-se como um desafio nada simples do ponto de vista epistemológico, bem como do ponto de vista

3 Trata-se da pesquisa doutoral de autoria de Camila Ferreira da Silva com o título provisório "Génese e consolidação dos campos académicos em (Ciências da) Educação no Brasil e em Portugal" que é orientada por Mariana Gaio Alves. 
operacional. E isso porque a própria noção do que tem sido denominado como "Sociologia da Educação" neste país ganha centralidade no exercício intelectual aqui empreendido. Parte-se, pois, da clareza de que as decisóes metodológicas acabam por situar-nos em determinadas porçôes da realidade social mais ampla, o que, neste caso, implica dizer que este artigo náo pretende mapear a totalidade da SE desenvolvida em Portugal, e sim analisar o desenvolvimento da relação entre as duas áreas do conhecimento que a compóem [Sociologia e Educação] no espaço académico já institucionalizado das Ciências da Educação em Portugal.

A combinação entre as abordagens quantitativa e qualitativa permitiu, portanto, de maneira mais geral, a operacionalizaçáo do presente estudo. Tal combinação pode ser compreendida como um Mixed Method (CRESWELL, 2012), no qual procurou-se um diálogo entre estratégias metodológicas diversificadas, nomeadamente: colecta, organização, tratamento e análise de dados secundários; revisão de literatura; e exercício exploratório analítico-relacional.

Os dados secundários que serviram de base para este artigo foram extraídos das páginas eletrónicas da Direcção Geral de Ensino Superior Portuguesa $(\mathrm{DGES})^{4}$ e dos programas de mestrado e doutoramento na área disciplinar das Ciências da Educação. $\mathrm{O}$ trabalho posterior à colecta de tais dados permitiu-nos construir um panorama das denominaçóes dos programas em questão, bem como de suas linhas de investigação e dos próprios pesquisadores associados a estes programas - este trabalho de caracterização possibilitou a identificação de espaços de desenvolvimento da Sociologia da Educação nos programas em questáo. Notadamente, este mapeamento forneceu um quadro actual que permitiu identificar os espaços de desenvolvimento da Sociologia da Educação frente às demais áreas do conhecimento no âmbito das Ciências da Educação em Portugal, contudo, não seria o quadro suficiente para a compreensão do fenómeno mais amplo que traduz a relação entre Sociologia e Educação no contexto supracitado.

Foi com base nesta compreensão que a revisão de literatura constituiu elemento essencial para o debate aqui promovido, uma vez que esta

4 http://www.dges.mctes.pt/DGES/pt. Último acesso em 27 de agosto de 2015. 
técnica viabilizou o contacto com trabalhos de referência acerca do desenvolvimento histórico da Sociologia da Educação em Portugal - os quais tornaram-se indispensáveis no desenvolvimento de uma perspectiva sócio histórica explicativa que se encontra substanciada na secção seguinte deste artigo. Para além do trabalho com os dados secundários e a revisão de literatura, o esforço aqui empreendido pode ser expresso como um tipo de estudo exploratório analítico-relacional, uma vez que: náo existem muitas investigaçóes que analisem a Sociologia da Educação desenvolvida em Portugal sob o domínio das Ciências da Educação e, em função da natureza do objecto de investigação e dos dados coletados, a perspetiva privilegiada neste artigo centra-se em um exercício que buscou relacionar aspectos históricos e hodiernos para compreender a relação entre Sociologia e Educação neste contexto.

\section{A Sociologia da Educação em Portugal: breve retrospectiva sócio histórica}

Partimos do pressuposto de que

[...] a sociologia da educação tem sido desenvolvida a partir de contribuições e pesquisas que procedem quer do campo da sociologia, quer do campo da educação. Esta situação, aliás, não é nova em termos da história da disciplina, nem é exclusiva do contexto português (AFONSO, 2010, P. 26).

Nestas condiçóes, importa explicitar o modo como esta dualidade se tem refletido no processo de desenvolvimento da Sociologia da Educação em Portugal.

Em Portugal, no plano da docência, terá sido primeiramente no contexto institucional das Ciências de Educação que se verificou a entrada das Ciências Sociais (em que se inclui a Sociologia). Designadamente, essa entrada terá sido sancionada pela respectiva inclusão nos planos de estudos de cursos de formação de professores da Faculdade de Letras de Lisboa em 1901 e mais tarde, depois da implantação da $1^{\text {a }}$ República, da Faculdade de Letras da Universidade de Coimbra em 1911 (STOER, 1992). Já enquanto área de especializaçáo leccionada em cursos de Sociologia, a Sociologia da Educaçáo só muito mais tarde foi instituída, uma vez que apenas depois do 25 de Abril de 1974 se criaram no nosso país cursos universitários nesta área disciplinar (COSTA, 1992). 
No plano da pesquisa científica, é durante os anos de 1960 que a Sociologia da Educação começa a registar em Portugal alguns desenvolvimentos, os quais são mais significativos e sistemáticos no campo da sociologia. $\mathrm{Na}$ área das Ciências de Educação, como assinala Nóvoa (1991), a premência em responder a necessidades de formaçáo de professores e educadores relegou para uma fase posterior a afirmação do domínio científico e a produção de conhecimento através da investigação. Noutros termos, a consolidação das Ciências de Educação realizou-se sobretudo como "resposta mais a uma ordem profissional do que a uma ordem científica" (PACHECO, 2004, p. 54).

Todavia, é sobretudo durante as décadas de 1960 e 1970 que despontam em Portugal condiçóes particularmente favoráveis ao desenvolvimento da Sociologia da Educação como área de magistério no ensino superior e também enquanto domínio de investigaçáo e produção de conhecimento. Esta situação articula-se com profundas transformações políticas e socioeconómicas que, neste período, se verificam no país. De facto, sendo o desenvolvimento da Sociologia da Educação neste período transversal a diferentes países é, muito provavelmente, particularmente abrupto em Portugal por comparação, por exemplo, com o Reino Unido. Neste último, Lauder, Brown e Halsey (2009) situam as origens da Sociologia da Educação na década de 1950 e assinalam o seu progressivo desenvolvimento ao longo de toda a segunda metade do século XX, sublinhando o papel da disciplina como apoio à reflexão e decisão sobre políticas educativas a implementar. Porém, os anos 1950 e 1960 correspondem, em Portugal, a um período de forte desinvestimento político no desenvolvimento, quer do sistema educativo, quer da área científica das ciências sociais, constituindo-se a década de 1970 como uma época de mudança profunda nesta matéria.

$\mathrm{Na}$ verdade, o crescimento substantivo da população estudantil em Portugal origina, principalmente a partir da década de 1970, a criação de vários cursos de ensino superior destinados à formação de professores. Tal oferta de cursos decorre do reconhecimento de que

A extensão da escolaridade obrigatória de 4 para 6 anos em 1968 e o aumento do número de alunos que passaram a procurar a escola nos diversos níveis de ensino pós-primário, durante as décadas de 70 e 80, vieram evidenciar carências crescentes do sistema educativo particularmente notórias [....] quanto a pessoal docente (ESTEVES, 2006, p. 152). 
Este incremento no número de cursos de formação de professores ocasiona um contexto institucional propício ao desenvolvimento das Ciências de Educaçáo, em que se inclui a Sociologia, enquanto área científica de ensino no quadro do ensino superior.

No que respeita ao domínio da Sociologia, poder-se-ia dizer, de algum modo, que a evolução é inversa. Isto é, a lecionação da Sociologia de Educação, enquanto subespecialização da Sociologia, só é possível em Portugal após o 25 de Abril de 1974, embora a afirmação deste domínio científico como campo de investigação e de produção de conhecimento já se viesse verificando anteriormente. Importa aqui recordar o trabalho de legitimação científica e institucional da sociologia conduzido no Gabinete de Investigaçóes Sociais (mais tarde Instituto de Ciências Sociais da Universidade de Lisboa) pela equipa liderada pelo professor Adérito Sedas Nunes, onde se concretizavam a maior parte das pesquisas sociológicas em Portugal naquela época, as quais também se centravam sobre questóes educativas (STOER, 1992; AFONSO, 2005).

Também no domínio das Ciências de Educação se identificam, durante os anos 1960, atividades de pesquisa e de produção de conhecimento científico que adquiriam algum vigor e que contribuíam para o desenvolvimento da área da sociologia da educação, nomeadamente no quadro da Fundação Calouste Gulbenkian onde trabalhou Rui Grácio (ABRANTES, 2004). Aliás, é nesse contexto institucional que se promovem um conjunto de estudos e conferências, inclusivamente convidando sociólogos da educação estrangeiros a visitar o nosso país (AFONSO, 2005).

Todavia, mesmo reconhecendo estes desenvolvimentos iniciais, a mudança política que culminou no 25 de Abril de 1974 constitui um marco fundamental. Por um lado, traduz-se no final de um regime autoritário que, como sublinha Afonso (2005, p. 151), "foi extremamente desfavorável à generalidade das ciências sociais e humanas, sobretudo as que assumiam um caráter problematizador e crítico" entre as quais se inclui a Sociologia de Educação. Por outro lado, significa o início de um período de forte investimento na expansão da escolaridade (prolongamento de trajetórias escolares) e da escolarização (alargamento de taxas de participação em educaçáo) dos portugueses.

Consequentemente, as últimas duas décadas do século XX são marcadas pelo intenso desenvolvimento da área científica da Sociologia da Educação, 
tanto em termos de número de alunos, docentes e investigadores no ensino superior, como também no plano do crescimento quantitativo e da diversificaçáo temática dos estudos e debates. Como assinala Afonso (2005, p. 154) "estando quase tudo por investigar no início da década de 1980, a sociologia da educação vai constituir-se a partir daí [...] elegendo no interior desse campo uma multiplicidade de objetos de pesquisa e reflexáo". A este propósito recorde-se que, em 1986, a adesão de Portugal à entáo Comunidade Económica Europeia é contemporânea da publicação da Lei de Bases do Sistema Educativo que ainda hoje, com algumas alteraçóes, se encontra em vigor no país. Ambos os acontecimentos testemunham um período de desenvolvimento económico que, do ponto de vista da política educativa, se caracterizou por um forte investimento no sector.

Nesse contexto, os cursos da área disciplinar da Educação, incluem os que se destinam a formação de professores e educadores e os de Ciências de Educação ${ }^{5}$, registando-se na época um significativo aumento do número de alunos destes cursos e um menos acentuado acréscimo do respectivo peso percentual no conjunto dos alunos no ensino superior ${ }^{6}$. Já na área das ciências sociais, comércio e direito, na qual se incluem os cursos em Sociologia, se verificou uma ligeira reduçáo do peso percentual de alunos, ainda que em termos absolutos o valor também tenha aumentado significativamente entre as mesmas duas datas ${ }^{7}$.

No que respeita ao desenvolvimento da investigação, este é também um período de expansão e consolidação, com o apoio dos órgãos nacionais de financiamento de pesquisa científica à área das ciências sociais e com a constituição de centros/unidades de investigação às quais é atribuído orçamento para o desenvolvimento das suas atividades. Uma parte significativa dos docentes e investigadores do ensino superior que protagonizaram estas dinâmi-

5 Os cursos em Ciências de Educação iniciaram-se em França em 1967 em três universidades distintas como refere Estrela (2008) e em Portugal na década de 1980.

6 Segundo dados consultados em "PorData-Base de Dados de Portugal Contemporâneo" (http://www.pordata. pt/) verificava-se, em 199I, que 19.47I alunos frequentavam cursos da área da educação (formação de professores e educadores e ciências de educação) correspondendo a 10,4\% do total de alunos do ensino superior; sendo os mesmo valores de 51.128 e 13,2\% em 2001.

7 Segundo dados consultados em "PorData-Base de Dados de Portugal Contemporâneo" (http://www.pordata. pt/) os alunos da área ciências sociais, comércio e direito correspondiam, respectivamente, a 36,4\% e 32,8\% do total em 199I e em 200I; sendo os valores absolutos de 69.850 e de 127.043. 
cas de mudança nas áreas da Sociologia e das Ciências da Educação haviam realizado os seus mestrados e doutoramentos no estrangeiro, verificando-se na época um movimento de "descoberta das realidades portuguesas" (STOER, 1992), nomeadamente para apoiar a decisão política inerente às reformas educativas então em curso no nosso país (AMBRÓSIO, 1992).

Um outro indício do intenso desenvolvimento das atividades de investigação e de ensino da Sociologia da Educação que marcou o final do século XX em Portugal, tanto no quadro da Sociologia como no âmbito das Ciências de Educação, consiste na constituição de duas sociedades científicas em que se enquadram especialistas e profissionais desta área disciplinar. É que a Associação Portuguesa de Sociologia fundada em 1985 e a Sociedade Portuguesa de Ciências de Educação surgida em 1990, foram desde então responsáveis pela organização periódica de debates, seminários e outros encontros científicos e profissionais, contribuindo para o desenvolvimento institucional deste domínio científico.

No início do século XXI, a pluralidade e a diversidade caracterizam a Sociologia da Educação em Portugal e noutros países. Do ponto de vista dos temas e objetos de estudo, uma muito breve análise retrospectiva permite identificar um interesse significativo pela análise das políticas educativas que tem acompanhado as transformaçóes que se têm operado em matéria de regulação destas políticas; a existência de trabalhos na área da educaçáo multicultural e intercultural, bem como no domínio das desigualdades de género e das desigualdades sociais de classe; e identificam-se, ainda, pesquisas sobre problemáticas diversas como a igualdade de oportunidades, a equidade social ou a justiça em educação e incidindo sobre os diferentes níveis de ensino (do jardim de infância ao superior) e as várias idades da vida (da infância à velhice). Do ponto de vista da produção científica, coexistem conjuntos de trabalhos de docentes e investigadores enquadrados nas Ciências da Educação com outros que se afirmam como desenvolvendo uma subespecialização da Sociologia. A este propósito, Canário (2005, p. 13) assinala a existência de uma "ambiguidade epistemológica" relacionada com o carácter plural ou singular da abordagem científica da educação, a qual pode ser considerada numa perspectiva de cruzamentos inter/multi/trans disciplinares ou como subespecializaçáo no interior de uma disciplina.

O debate sobre as convergências e divergências entre as duas comunidades de sociólogos da educação em Portugal tem vindo a ser sustentado por 
algumas análises sistemáticas publicadas durante a primeira década do século XXI. Uma dessas análises considera as atas dos principais congressos organizados pela Associação Portuguesa de Sociologia e pela Sociedade Portuguesa de Ciências de Educação entre 1985 e 2000, permitindo ao autor do trabalho (ABRANTES, 2004) sugerir a existência de poucos contactos entre as duas comunidades e identificar diferenças ao nível dos protagonistas e das suas pertenças institucionais, mas bastantes convergências em termos das temáticas abordadas e das metodologias de pesquisa escolhidas. Num texto posterior, baseando-se na análise de uma amostra intencional de trabalhos publicados em sociologia da educação entre 2004 e 2009, um outro autor não confirma totalmente a hipótese da diferenciação entre as duas comunidades científicas, argumentando que não existem divergências teóricas e metodológicas suficientemente profundas entre ambas (AFONSO, 2010). Não obstante, identifica a tendência para a Sociologia da Educação no quadro das Ciências da Educação privilegiar um pouco mais as estratégias metodológicas de cariz qualitativo (ainda que não descartando as quantitativas) e para abordar mais frequentemente objetos e contextos não-escolares; ao mesmo tempo que indica, sobre a Sociologia da Educação que se desenvolve enquanto subespecialização da Sociologia, um maior fechamento aos contributos das Ciências de Educação e um grau menor de interdisciplinaridade (AFONSO, 2010).

No debate em torno das convergências e divergências entre as duas comunidades de sociólogos da educaçáo, importa não escamotear as diferenças observadas no plano do reconhecimento e estatuto social de cada uma delas. Em Portugal, reconhece-se que as Ciências da Educação não têm "[...] atrás de si o estatuto científico e o reconhecimento social que a psicologia, a sociologia e outras ciências sociais adquiriram" (ESTRELA, 2008, p. 26). Também noutros países se indica que as Ciências da Educaçáo são tradiçóes intelectuais complexas e instáveis que necessitam constantemente de argumentar e fundamentar a sua legitimidade, por contraste com disciplinas que correspondem a conjuntos estáveis de conhecimentos apoiadas em teorias e métodos claramente demarcados (FURLONG; LAWN, 2011).

Reconhecendo a relevância de contextos institucionais de Ciências de Educação como um espaço importante para o desenvolvimento da Sociologia da Educação desde inícios do século XX, na secção seguinte deste artigo apresentam-se dados que permitem conhecer com mais detalhe o modo como 
a Sociologia da Educação integra programas de mestrado e doutoramento em Ciências da Educação.

\section{O lugar da Sociologia da Educação nas Ciências da Educação: o caso dos programas de mestrado e doutoramento portugueses}

A Direcção Geral de Ensino Superior de Portugal (DGES/Pt) disponibiliza, em sua página eletrónica, tabelas com toda a oferta de mestrados e doutoramentos em todas as áreas do conhecimento. $\mathrm{O}$ trabalho realizado a partir das informaçóes contidas em tais tabelas consistiu em identificar os cursos ligados à área disciplinar da Educação e, a partir disto, buscou-se compreender a presença da Sociologia da Educação no universo de temáticas e linhas de investigação ali presentes.

Num primeiro levantamento foram identificados 407 cursos ligados à Educação, os quais foram classificados nas seguintes categorias iniciais: 221 mestrados em ensino (dos quais 46 apresentavam problemas com acreditaçáo); 186 mestrados e doutorados académicos (dos quais 22 apresentavam também problemas com acreditação). Frente a estes números, foram necessárias algumas decisóes para a construção do corpus a ser estudado: os cursos não acreditados pela Agência Nacional de Acreditação do Ensino Superior (A3ES) foram descartados, uma vez que alguns destes cursos já haviam sido descontinuados anos atrás ou estavam com previsáo de descontinuidade para 2015; os mestrados em ensino também foram desconsiderados para o presente estudo, porque o objectivo destes mestrados é conferir habilitação profissional em áreas disciplinares para a docência no ensino básico; neste sentido, 164 cursos foram foco das decisóes de recorte seguintes.

Foi preciso recorrer a uma nova decisão de recorte no âmbito destes 164 cursos, uma vez que alguns cursos apareciam de forma duplicada por serem ministrados em parcerias estabelecidas entre diferentes instituiçóes ${ }^{8}$. No final, 154 cursos serviram de base para o mapeamento da Sociologia da Educação

8 Como exemplo destes casos tem-se o curso de doutoramento em Ciências da Educação da Universidade Nova de Lisboa (UNL), que aparece três vezes na listagem da DGES por ser realizado por meio de uma parceria entre a Faculdade de Ciência e Tecnologia (FCT) e a Faculdade de Ciências Sociais e Humanas (FCSH) da UNL e ainda o Instituto Universitário de Ciências Psicológicas, Sociais e da Vida (ISPA). 
na área ligada às Ciências da Educação em Portugal, sendo que o tratamento efectuado com tais cursos seguiu o seguinte caminho: 1) partiu-se das denominaçóes dos cursos para iniciar a identificação daqueles correlacionados à Sociologia da Educação, nesta etapa cursos com denominaçóes como "Educação e Sociedade" e "Educaçáo Social" foram seleccionados; 2) alguns cursos, tanto de mestrado, quanto de doutoramento, recebem a denominação de "Educação" ou "Ciências da Educação" e, por isso, foram seleccionados para posterior análise de suas linhas de investigação - o intuito consistiu em buscar detectar possíveis linhas ligadas ao desenvolvimento de pesquisas em Sociologia da Educação.

Ademais, dentre os 154 cursos analisados, 53 (ou seja, aproximadamente $34 \%)$ encaixavam-se nestes pré-requisitos. Foi preciso ir ainda mais a fundo para visualizar em quais destes 53 cursos a presença da Sociologia da Educação se confirmava: a estratégia utilizada contou com a visita aos sítios eletrónicos dos programas de mestrado e doutorado seleccionados até esta etapa para o reconhecimento de linhas de investigação ligadas à SE. Temos que, dos 53 cursos, 21 (em torno de 40\%) acabaram por ser descartados por náo apresentarem nenhum vínculo com a $\mathrm{SE}^{9}$ e, finalmente, nosso corpus constituiu-se de 32 cursos $(60 \%$ com relaçáo aos 53 cursos que serviram de base para este último recorte metodológico).

Após todos estes movimentos em prol do tratamento das informaçôes contidas no material compilado a partir dos dados da DGES/Pt, a análise relacional do corpus aqui construído é capaz de revelar elementos importantes para a compreensão da actual configuração da Sociologia da Educação desenvolvida em Portugal. Neste sentido, dois entendimentos fazem-se necessários antes de caracterizarmos os cursos sobre os quais nos debruçamos, nomeadamente: ao delimitarmos as denominadas Ciências da Educação como campo de estudo, estamos assumindo que o presente estudo não se propóe a abarcar

9 Faz-se mister referir aqui a dificuldade encontrada neste processo de consulta às páginas eletrónicas dos cursos de mestrado e doutoramento das mais diversas universidades portuguesas, uma vez que nem todas as universidades disponibilizam informações acerca de seus programas, tais como, linhas de especialização/ investigação, docentes ou produção académica. Quatro destes 21 cursos (19\%) foram descartados por insuficiência de informações para enquadramento no presente estudo - nomeadamente: mestrado em Educação Social e Comunitária da Universidade da Beira Interior; doutoramento em Ciências da Educação da Universidade Católica Portuguesa; doutoramento em Ciências da Educação da Universidade de Trás-osMontes e Alto Douro; e mestrado em Educação da Universidade dos Açores. 
a totalidade da Sociologia da Educação desenvolvida em Portugal (que pode ser encontrada e mapeada em diferentes domínios com destaque para o da própria Sociologia); e, ainda assim, por questóes metodológicas, as decisóes que marcam a trajectória deste estudo tornam evidente a necessidade de eleger como domínios da SE nos programas de mestrado e doutoramento analisados aquilo que se encontra institucionalizado em cada programa - o que significa dizer que, mesmo no domínio das Ciências da Educação, a SE que mapeamos aqui provavelmente não engloba a totalidade das investigaçóes realizadas no âmbito da área disciplinar da Educaçáo que tomam a Sociologia como suporte epistemológico, teórico e/ou metodológico.

Iniciemos a caracterização dos 32 cursos pela localizaçáo geográfica dos mesmos, porém, não façamos este exercício descolado dos dados que supra citamos neste tópico da discussáo. Observemos a figura 1, abaixo:

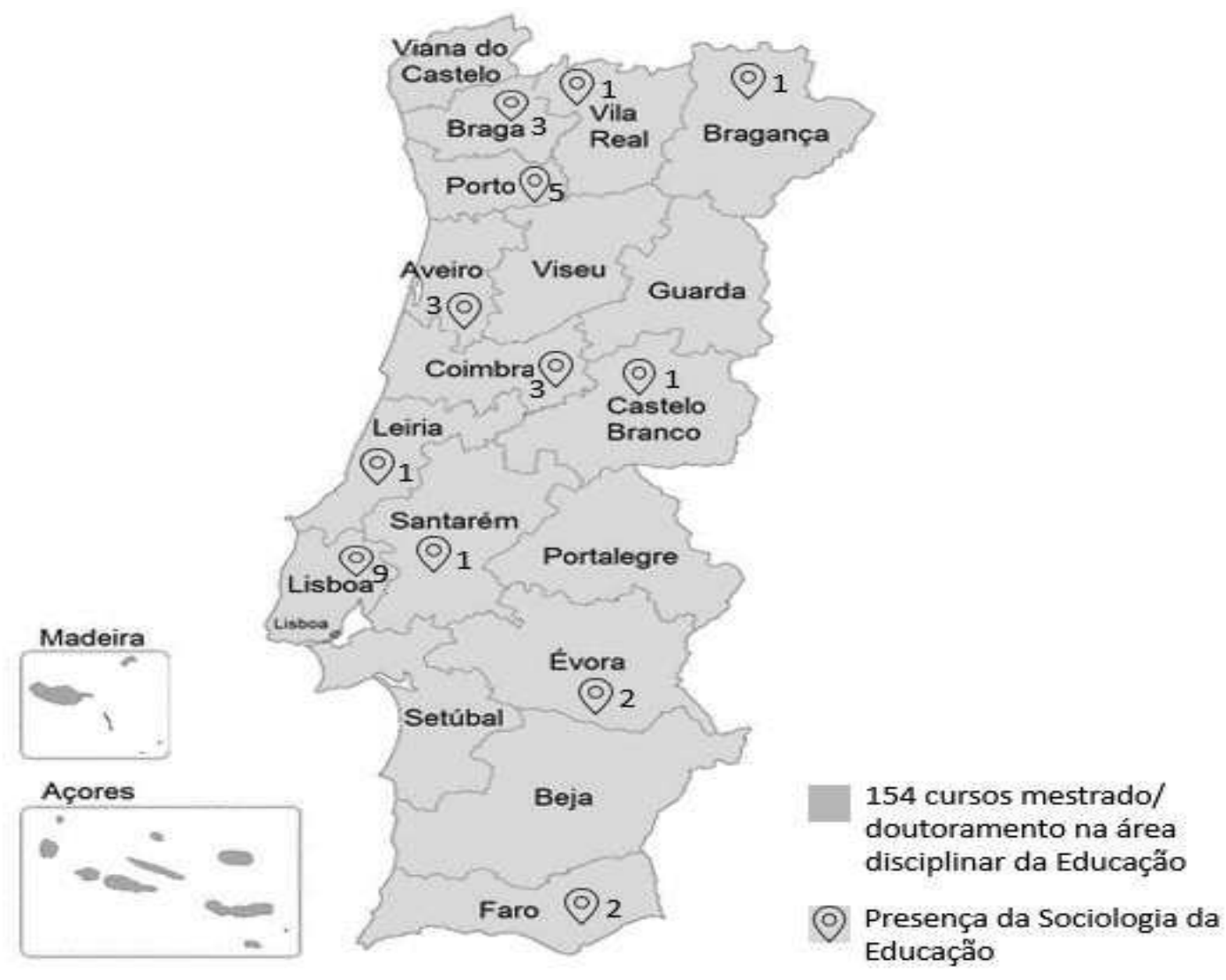

Figura I - Mapeamento da Sociologia da Educação no âmbito da área disciplinar ligada à Educação/Portugal

Fonte: As autoras (20I6). 
O mapa em questão revela a expressividade da Educação enquanto área de formação e investigação no contexto português: é possível observar que os 154 cursos de mestrado e doutoramento, contabilizados neste estudo, estendem-se por todos os distritos administrativos de Portugal. Pacheco (2004), há mais de uma década, ao enfrentar o exercício de pensar os percursos de investigação no âmbito do campo educacional em Portugal, afirmava que este campo encontrava-se em uma fase de crescimento em direcção à sua consolidação. Do ponto de vista da institucionalização dos cursos de mestrado e doutoramento em universidades públicas e privadas portuguesas, tal consolidação parece revelar-se acentuada. Se acrescentarmos ainda o número de mestrados profissionais, já citados anteriormente mas náo representados no mapa [175 cursos, excetuando-se aqueles que apresentam problemas de acreditação], torna-se ainda mais evidente a elevada oferta de cursos no âmbito da área do conhecimento ligada à Educação.

Os processos de consolidação deste campo de formação e investigação encontram-se directamente relacionados com a diversidade de áreas que, historicamente, estabelecem relaçóes com as chamadas Ciências da Educação ${ }^{10}$, encontrando-se a Sociologia da Educação nesta relação fronteiriça entre as duas áreas do conhecimento que a compóem. A Figura 1 consegue sintetizar, por sua vez, o espaço ocupado pela SE no contexto mais amplo da oferta de cursos de mestrado e doutoramento cadastrados na DGES/Pt na área disciplinar das Ciências da Educação. Tratemos, pois, deste espaço, geográfico e simbólico, de produção cultural académica.

O exercício de objectivação aqui empreendido acabou por revelar que existem cursos, no campo da Educação, que estabelecem relaçóes com a Sociologia da Educação em doze distritos portugueses, sendo eles em ordem crescente no que respeita à presença da SE: Vila Real, Bragança, Castelo Branco, Leiria, Santarém (cada um apresenta um curso); Évora e Faro (com dois cursos em cada distrito); Aveiro, Braga e Coimbra (três cursos em cada um deles); Porto (com cinco cursos); e Lisboa (com nove cursos). Lisboa e Porto destacam-se como os distritos com maiores quantidades de cursos de mestrado e doutoramento que englobam a SE, dado que dialoga com o facto de estes distritos também destacarem-se no quadro mais amplo da oferta em Educação (apresentam, respectivamente, 42 e 35 cursos).

10 Acerca desta discussão, que ultrapassa os objectivos deste artigo, consultar Furlong e Lawn (2011). 
Os 32 cursos aqui analisados dividem-se da seguinte maneira: 23 referem-se a cursos de mestrado (o que equivale a, aproximadamente, $72 \%$ ), enquanto 9 referem-se a cursos de doutoramento (28\%). Tal divisáo náo parece, à primeira vista, levantar quaisquer discussóes em torno da discrepância que revela, porém, se tomarmos como referência para o debate a continuidade dos estudos dos mestrandos e de suas investigaçóes, a diferença acentuada entre o número de mestrados e doutoramentos que oferecem linhas de investigação ligadas à SE pode significar uma ruptura significativa nas trajectórias dos pesquisadores em formação: o escasso número de doutoramentos que contemplam linhas em SE pode representar para os estudantes a necessidade de mudar de linha investigativa ou mesmo mudar de área, abandonando as Ciências da Educação.

A oferta de tais cursos ocorre por meio de 19 diferentes instituições de ensino superior portuguesas, as quais podem ser representadas da seguinte maneira:

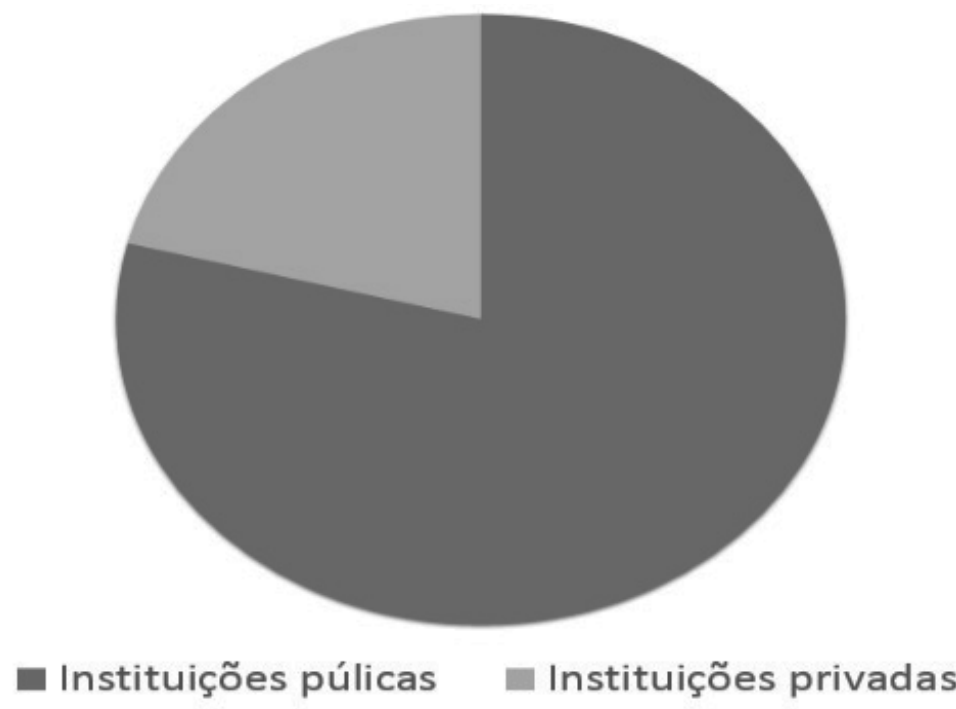

\section{Gráfico I - Distribuição institucional da Sociologia da Educação no âmbito da área disciplinar ligada à Educação/Portugal}

Fonte: As autoras (2016).

A evidente supremacia das instituições públicas traduz o gráfico acima, vejamos como isto se coloca em números: 15 destas instituiçóes são públicas (o que representa $79 \%$ do total) e, de outro lado, 4 são privadas (ou $21 \%$. 
Esta situação não é surpreendente, tendo em conta que as instituiçôes públicas de ensino superior são, em Portugal, claramente maioritárias do ponto de vista do número de docentes e de alunos. Neste âmbito, assinala-se que há um caso em que podemos visualizar uma parceria entre público e privado que corresponde à parceria estabelecida entre a Universidade Nova de Lisboa e o Instituto Universitário de Ciências Psicológicas, Sociais e da Vida para a oferta do doutoramento em Ciências da Educação. As restantes instituiçóes públicas das quais estamos tratando são: Instituto Politécnico de Bragança; Instituto Politécnico de Castelo Branco; Universidade de Coimbra; Instituto Politécnico de Leiria; Instituto Politécnico de Lisboa; Instituto Universitário de Lisboa (ISCTE); Universidade de Lisboa; Universidade Nova de Lisboa; Instituto Politécnico de Santarém; Instituto Politécnico do Porto; Universidade do Porto; Universidade de Aveiro; Universidade de Évora; Universidade de Trás-os-Montes e Alto Douro; Universidade do Algarve e Universidade do Minho. Já as instituiçóes privadas são: Universidade Lusófona de Humanidades e Tecnologia; Universidade Católica Portuguesa; Universidade Portucalense Infante D. Henrique; e o já citado ISPA.

Tal cenário não demonstra apenas a expressiva participação das instituiçôes públicas no que tange a estes graus de ensino acima referidos, evidenciando, sobretudo, a força que as universidades públicas possuem no que se refere ao desenvolvimento de investigaçóes ligadas à Sociologia da Educaçáo. Os números a que aqui chegamos permitem-nos afirmar que a $S E$ que vem sendo desenvolvida na esfera das Ciências da Educação em Portugal deriva, maioritariamente, de instituiçóes públicas; se somarmos isto ao facto de as instituiçóes privadas apresentarem uma participação muito mais expressiva na oferta de mestrados profissionais, uma clara divisão das tarefas entre os diferentes tipos de instituiçóes começa a se desenhar neste contexto.

As linhas de investigaçáo dos programas de mestrado e doutoramento aqui considerados serviram de informaçáo crucial para o exercício de análise dos diferentes domínios a que a Sociologia se encontra vinculada no contexto das Ciências da Educação. Em um primeiro momento, é possível visualizar a relação entre as linhas pertencentes à esfera da Sociologia da Educação e as demais linhas contempladas pelos 32 programas sobre os quais estamos a nos debruçar, a relação numérica entre elas é a seguinte: 90 linhas ligadas à SE são 
apresentadas nas páginas eletrónicas dos referidos programas ${ }^{11}$; estas, por sua vez, encontram-se em um universo de 213 linhas, o que implica afirmar que, do total de linhas de pesquisa ofertadas nestes programas, a SE marca presença em $42 \%$ delas.

Vejamos, entáo, o que estas linhas revelam acerca do que é denominado de Sociologia da Educação no corpus aqui investigado, a Tabela 1, abaixo, expóe uma compilação das linhas por meio de categorias mais amplas:

Tabela I - A Sociologia da Educação nos mestrados e doutoramentos da área disciplinar da Educação/Portugal - o que dizem as linhas de investigação?

\begin{tabular}{lcc}
\hline Categoria de compilação & $\begin{array}{c}\text { Quantidade } \\
\text { absoluta }\end{array}$ & Percentual \\
\hline Educação, Sociedade e Desenvolvimento & 21 & $23,5 \%$ \\
Educação e Sociologia & 19 & $21 \%$ \\
Ensino Superior & 9 & $10 \%$ \\
Educação de Adultos & 8 & $9 \%$ \\
Sociologia da Família e Educação & 7 & $8 \%$ \\
Sociologia da Juventude e Educação & 5 & $6 \%$ \\
Desigualdades sociais e inclusão & 5 & $6 \%$ \\
Ciência e Cultura & 4 & $4,5 \%$ \\
Género e Educação & 3 & $3 \%$ \\
Sociologia da Infância e Educação & 3 & $3 \%$ \\
Sociologia do Trabalho e Educação & 2 & $2 \%$ \\
Movimentos sociais & 2 & $2 \%$ \\
Outros & 2 & $2 \%$ \\
\hline TOTAL & 90 & $100 \%$ \\
\hline
\end{tabular}

Fonte: As autoras (2016).

As categorias de compilação, como a própria denominação sugere, foram criadas para abarcar diferentes linhas de investigação que podem ser agrupadas em função de sua relação mais ampla. Educação, Sociedade e Desenvolvimento e

II A identificação destas linhas foi possivel graças às descrições contidas nas páginas eletrônicas dos cursos analisados, tais descrições acabam por revelar os diferentes dominios que compõem este campo. 
Educação e Sociologia destacam-se e, juntas, somam 44,5\% do total de linhas: a primeira é composta por linhas que possuem como característica principal um carácter mais interventivo e apresenta, de um lado, linhas concatenadas com o desenvolvimento social e comunitário (tais como, "Educação e desenvolvimento comunitário", "Desenvolvimento local" e "Educação social e intervenção comunitária") e, de outro, com o desenvolvimento individual (a exemplo de "Sociologia do desempenho escolar" e "Biografias e desafectação escolar"); já a segunda categoria condensa linhas de investigação mais gerais e que acabam por anunciar a relação entre as duas áreas que compóem a SE, a exemplo de "Ciências Sociais", "Sociologia da Educação" e "Análise Social da Educação".

Ensino superior é uma categoria formada por linhas que apresentam clara propensão às investigações preocupadas com análises das políticas que afectam este grau de ensino ("Políticas de ciência e ensino superior", "Governação do ensino superior" e "Gestão e avaliação do ensino superior" são exemplos que demonstram isto). Educação de Adultos, por sua vez, engloba linhas gerais - como, "Educação de Adultos" e "Formação de Adultos" -, ao passo que demonstra um debate importante que compóe esta área de pesquisa com as próprias denominaçóes de algumas de suas linhas, é o caso de "Educação ao longo da vida" e "Perspectivas e práticas de educação de adultos".

As sete linhas que compóem a categoria Sociologia da Família e Educação revelam temas que vão desde a educação familiar até as dinâmicas familiares e não esquecendo da relação entre família e escola. Em sequência, Sociologia da Juventude e Educaçáo é composta por linhas que revelam preocupaçóes com temas ligados à educação, cultura e cidadanias dos jovens. A própria denominação da categoria seguinte, Desigualdades sociais e inclusão, já é reveladora do teor das linhas que condensa, "Descendentes de imigrantes e Educação" é, pois, a linha que ganha destaque nesta categoria, justamente, por fugir às denominaçóes mais genéricas e globais que carregam o termo "desigualdades sociais".

Temos ainda: Ciência e Cultura, categoria marcada por linhas que apresentam a própria ciência como objecto de estudo, com ênfase na cultura académica, nos discursos e práticas científicos; Género e Educação é composta pelas seguintes linhas "Género, Educação e Cidadanias", "Feminilidades e masculinidades" e "Corpo, sexualidades e gravidez adolescente"; Sociologia da Infância e Educação apresenta linhas que buscam aliar os universos infantis e 
escolares com ênfases nas culturas infantis e na questão do género; Sociologia do Trabalho e Educação apresenta as linhas "Trabalho e Educação" e "Formação, Trabalho e recursos humanos"; e, por fim, a categoria Outros traz duas linhas que não se enquadraram nas anteriores, nomeadamente "Sistemas educativos comparados" e "Herança educativa e animação sócio-cultural"12.

A diversidade de temáticas reveladas por todas estas linhas de investigaçáo e pelas suas respectivas categorias de compilação é um elemento importante para compreendermos aquilo que tem sido legitimado como Sociologia da Educação no campo académico específico da investigação em Educação ou Ciências da Educação no contexto português. Obviamente, as lutas simbólicas inscritas no campo científico português expressam as divergências e as aproximaçóes entre aqueles que fazem a SE no espaço da Sociologia e aqueles que a fazem em outros espaços (ABRANTES, 2004). O que o mapeamento aqui apresentado acaba por demonstrar, além do lugar que a SE vem ocupando no espaço global das Ciências da Educação em Portugal, são as especificidades e os contornos que a Sociologia ganhou no domínio da Educação.

\section{Conclusões - Sociologia e Educação: conflitos e lutas no campo científico português}

O processo de autonomização de um espaço específico das Ciências da Educação no plano mais amplo do campo científico português esteve interrelacionado, como demonstramos, com a necessidade inicial de formar profissionais na área da docência, remetendo a consolidação deste espaço enquanto produtor de conhecimentos próprios por meio de investigaçóes para segundo plano e para uma fase posterior em sua história. Além disso, dois elementos são essenciais para compreender como se deu (e como ainda se dá) o desenvolvimento da Sociologia da Educação nas Ciências da Educaçáo neste contexto, são eles: os processos históricos ligados à ditadura enfrentada por Portugal no século passado, que influenciaram deterministicamente o desenvolvimento científico do país; e as distinçóes simbólicas reveladas pelo reconhecimento

12 Inicialmente, o presente estudo pretendeu analisar também a formação e a produção dos professores e pesquisadores que compõem os programas de mestrado e doutoramento aqui analisados, contudo, em função da escassa informação disponibilizada nas páginas eletrónicas dos programas acerca destes agentes, resolvemos não enveredar por este debate, tampouco produzir dados a partir de informações incompletas. 
e estatuto científico e social, que revelam o grau de legitimidade do que é desenvolvido nas Ciências da Educação frente à totalidade da comunidade científica portuguesa.

Neste cenário de lutas pelo direito de discursar acerca de um objecto ou sob o aparato de determinada área, a Sociologia da Educação salienta, de forma concomitante, o diálogo e o hiato que existem entre a Sociologia e as Ciências da Educação - a literatura internacional, por sua vez, tem demonstrado que estes conflitos não são exclusivos da realidade portuguesa. $\mathrm{O}$ presente estudo insere-se neste debate e buscou contribuir com o aprofundamento do conhecimento da SE em Portugal por meio do enfrentamento da indagação: qual o lugar ocupado pela Sociologia da Educação nas Ciências da Educação? Analisar, portanto, a SE a partir deste espaço específico da produção académica significou tomar não somente uma parte do todo, significou também tomar analiticamente a parte considerada menos legítima ou periférica pela literatura especializada (ABRANTES, 2004; AFONSO, 2010), dentro das lutas simbólicas travadas neste campo: a relação entre periferia e centro pode ser uma chave explicativa interessante para pensar este debate, pois, no âmbito da comunidade científica contemporânea, ela faz emergir elementos como prestígio, status, legitimidade, autoridade, reputação, circulação de conhecimento, etc. (BOURDIEU, 1983; NEVES, 2009). Naturalmente, esta afirmação de que a SE desenvolvida nas Ciências da Educação ocupa um lugar hierarquicamente desafavorável em relação àquela desenvolvida na Sociologia deve ser tomada como uma releitura da própria literatura disponível e também como uma espécie de hipótese que o presente estudo levanta e que, certamente, deve vir a problematizar futuramente.

O exercício de que se dá conta neste artigo constitui uma primeira etapa de um projeto de investigaçáo em curso, resultando numa leitura abrangente que será posteriormente aprofundada, mas que por agora permite destacar os seguintes aspetos sobre o lugar que a SE ocupa actualmente nas Ciências da Educação: a) em um primeiro olhar, 32 cursos pode náo representar um número muito significativo do ponto de vista estatístico, porém, esta compreensáo complexifica-se ao levar em consideraçáo a diversificaçáo característica do campo das Ciências da Educação em função do número elevado de áreas que têm dialogado com a educação historicamente e das áreas de especialização que o próprio desenvolvimento deste campo tem demandado nas últimas 
décadas (ALVES; AZEVEDO; GONÇALVES, 2013; FURLONG; LAWN, 2011), bem como o facto de o prestígio de determinada área do conhecimento não estar, necessariamente, ligado ao número de cursos que a contemplam; b) a SE está presente, no âmbito dos mestrado e doutoramentos em Ciências da Educação, em doze distritos portugueses (quase 70\%) e sua presença ganha ainda mais notoriedade por ter o maior número de cursos na capital e em outras cidades portuguesas importantes; c) a diversificação de temas ligados à SE nestes cursos é atravessada pela presença da Política enquanto perspectiva das Ciências Sociais e também enquanto objecto de investigação, o que pôde ser observado pelas descriçóes das linhas de investigação e está em concordância com as conclusóes das análises de Abrantes (2004) e Afonso (2005).

Por fim, as próprias limitaçóes do exercício aqui realizado apontam para a necessidade de aprofundamento futuro. Foi possível mapear, quantificar e caracterizar a Sociologia da Educação a partir dos cursos analisados, mas questóes acerca das perspectivas metodológicas, epistemológicas e teóricas que a marcam demandam informaçóes mais específicas e outras técnicas de trabalho que podem ser empreendidas em fases posteriores do estudo. Análises em torno dos pesquisadores, dos estudantes, dos seus temas de investigação, bem como das teses já defendidas podem constituir possíveis caminhos de pesquisa futura.

\section{Referências}

ABRANTES, P. Tendências e controvérsias em sociologia da educaçáo. Lisboa: Editora Mundos Sociais, 2010.

ABRANTES, P. Sociologia e ciências de educação: a distância entre nós. Revista Sociologia Problemas e Práticas, Lisboa, n. 45, p. 117-130, maio 2004.

AFONSO, A. Caminhos, cumulatividade e ambivalência. In: ABRANTES, P. (org.). Tendências e controvérsias em sociologia da educaçáo. Lisboa: Editora Mundos Sociais, 2010.

AFONSO, A. J. A sociologia da educação em Portugal. Elementos para a configuração do "estado da arte". In: TEODORO, A.; Torres, C. A. Educação crítica e utopia - perspetivas para o século XXI. São Paulo: Cortez Editora, 2005.

ALVES, M. G.; AZEVEDO, N. R. GONÇALVES, T. N. R. (Edt.). Educational theory informing educational research. Scenarios and lines of flight. Caparica: UIED/FCT, Universidade Nova de Lisboa, 2013. 
AMBRÓSIO, T. As ciências da educação em Portugal. Um debate em busca de um lugar entre as ciências do homem e da sociedade. In: GAGO, J. M. O Estado das Ciências em Portugal. Lisboa: Publicações D. Quixote, 1992.

APPLE, M. W.; BALL, S. J.; GANDIN, L. A. The Routledge International Handbook of the Soiology of Education. London and New York: Routledge, 2010.

BALL, S. The Routledge Falmer in Sociology of Education. London and New York: Routledge Falmer, 2004.

BOURDIEU, P. O campo científico. In: ORTIZ, R. (org.). Pierre Bourdieu. "Grandes cientistas sociais”. São Paulo : Ática, 1983.

CANÁRIO, R. O que é a escola? Um olhar sociológico. Porto: Porto Editora, 2005.

COSTA, A. F. O que é sociologia? Lisboa: Difusão Cultural, 1992.

CRESWELL, J. W. Educational research: planning, conducting and evaluating quantitative and qualitative research. 4. ed. Boston: Pearson Education, 2012.

ESTEVES, M. (2006). Formação de Professores: das concepçôes às realidades. In L. Lima, J. A. Pacheco, M. Esteves, \& R. Canário, A Educaçáo em Portugal (1986-2006). Alguns Contributos da Investigaçáo. Lisboa: Conselho Nacional de Educação.

ESTRELA, T. As Ciências da Educação, Hoje. In: SOUSA, J. M. Educaçáo para o Sucesso: Políticas e Actores. Actas do IX Congresso da SPCE-Funchal. Lisboa: Legis Editora - SPCE, 2008 .

FURLONG, J.; LAWN, M. (edt.). Disciplines of education. Their role in the future of education research. Abingdon, Oxon: Routledge, 2011.

LAUDER, H.; BROWN, P.; HALSEY, A. H. Sociology of education: a critical history and propects for the future. Oxford Review of Education, Oxford, v. 35, n. 5, p. 569-585, 2009.

NEVES, F. M. A diferenciação centro-periferia como estratégia teórica básica para observar a produção científica. Rev. Sociol. Polít., Curitiba, v. 17, n. 34, p. 241-252, out. 2009.

NÓVOA, A. As ciências de educação e os processos de mudança. In: Nóvoa, A.; CAMPOS, B.; PONTE, J. P.; SANTOS, B. (orgs.). Ciências da educaçáo e mudança. Porto: Sociedade Portuguesa de Ciências da Educação, 1991.

PACHECO, J. A. Dos tempos e lugares do campo educacional: uma análise dos percursos de investigação em Portugal (1900-2000). Revista Brasileira de Educaçáo, Rio de Janeiro, n. 25, p. 53-66, jan./abr. 2004. 
O lugar da sociologia da educação nas ciências da educação: o caso dos programas de mestrado e doutoramento portugueses | Camila Ferreira da Silva e Mariana Gaio Alves

STOER, S. Notas sobre o desenvolvimento da sociologia da educação em Portugal. In: ESTEVES, A. J.; STOER, S. A sociologia na escola - professores, educaçáo e desenvolvimento. Porto: Edições Afrontamento, 1992.

Recebido em: 10.07.2015

Aceito em: 20.10.2015

\section{The place of Sociology of Education in the Education Sciences: the case of the Portuguese masters and PhD programs}

\section{Abstract}

To consider analytically any areas of research is an exercise that brings out issues of conceptual and epistemological orders and involves the struggles in a particular scientific field for the legitimacy of a structure, agents, capital and positions in game. Such understanding formed the mainstay to this article, which has the general objective to contribute to a wider knowledge of Sociology of Education in Portugal. To this end, the aforementioned area was taken from his facet as teaching area in masters and doctoral courses in the framework of Educational Sciences. The combination done here between a sociohistorical summary, on the one hand, and the current characterization from the above courses, on the other, enabled us better to understand what is legitimized as Sociology of Education, and the place it occupies in the space of Educational Sciences.

Keywords: Scientific field; Sociology of Education; Educational Sciences; Portugal. 